Supporting Information

\title{
Peptide-Directed Assembly of Single-Helical Gold Nanoparticle Superstructures Exhibiting Intense Chiroptical Activity
}

Andrea D. Merg, ${ }^{\dagger}$ Jennifer C. Boatz,,${ }^{\dagger}$ Abhishek Mandal, ${ }^{\dagger}$ Gongpu Zhao, ${ }^{\star}$ Soumitra MokashiPunekar, ${ }^{\dagger}$ Chong Liu, Xianting Wang, ${ }^{+}$Peijun Zhang, ${ }^{*}$ Patrick C. A. van der Wel, ,* and Nathaniel L. Rosi*广

${ }^{\dagger}$ Department of Chemistry, University of Pittsburgh, 219 Parkman Ave., Pittsburgh, Pennsylvania 15260, United States

Department of Structural Biology, University of Pittsburgh, School of Medicine, 3501 Fifth Avenue, Pittsburgh, Pennsylvania 15260, United States 


\section{Supplementary Data}
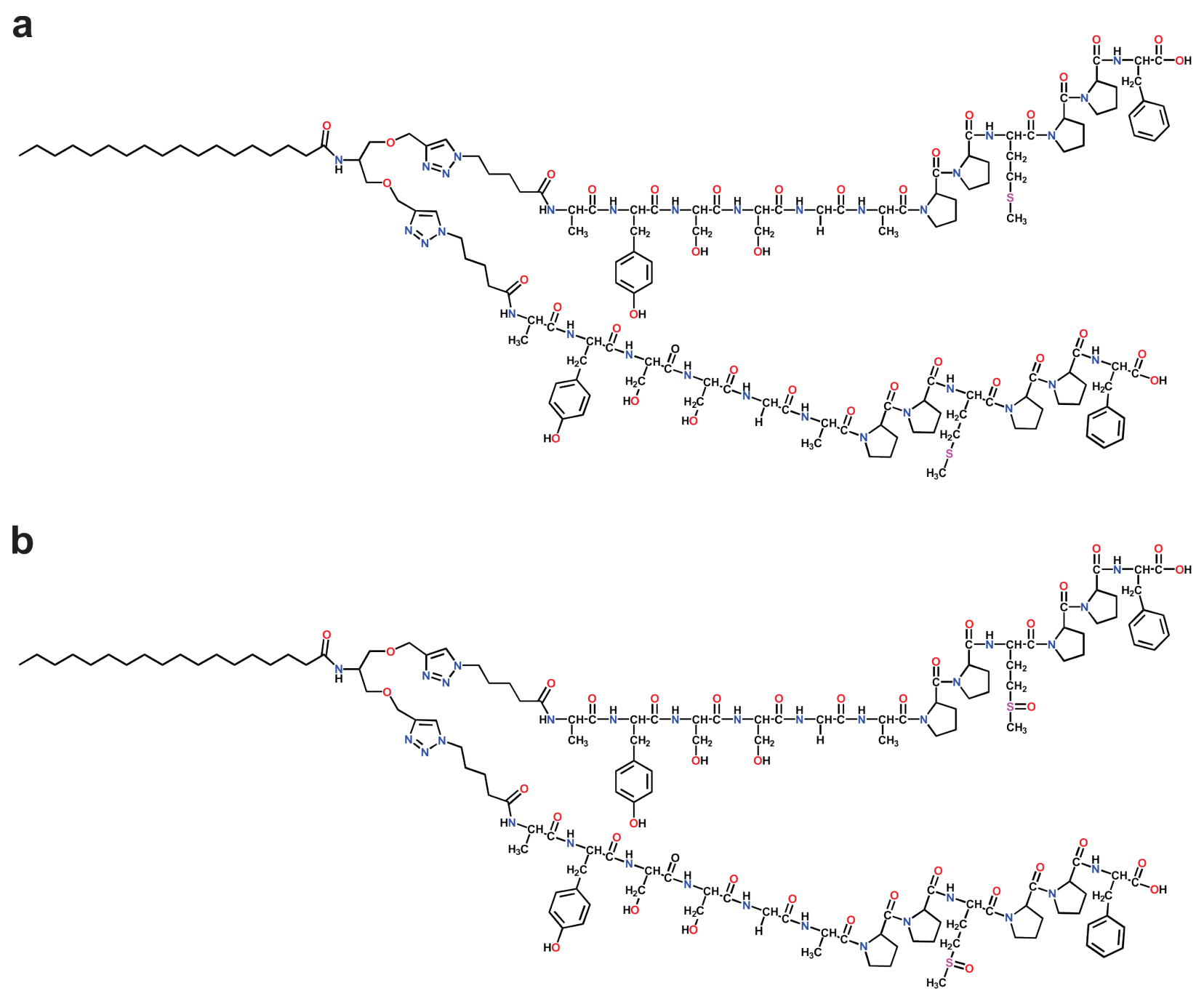

Figure S1. Chemical structure of (a) $\mathrm{C}_{18}-\left(\mathrm{PEP}_{\mathrm{Au}}\right)_{2}$ and (b) $\mathrm{C}_{18}-\left(\mathrm{PEP}_{\mathrm{Au}}^{\mathrm{M}-\mathrm{Ox}}\right)_{2}$. 
a

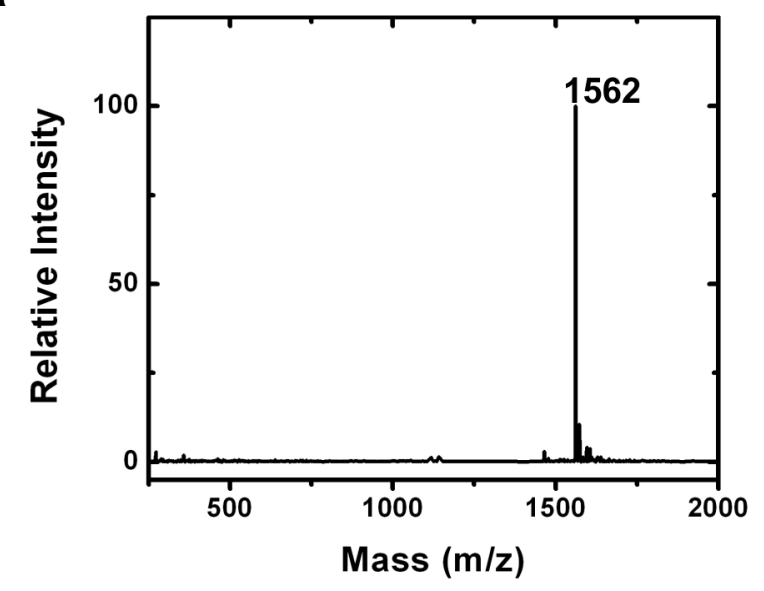

b

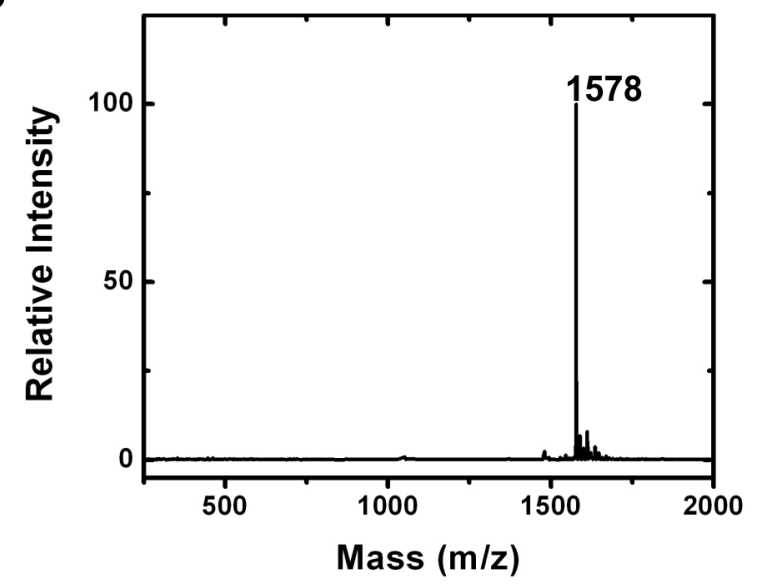

Figure S2. LCMS spectra of (a) $\mathrm{C}_{18}-\left(\mathrm{PEP}_{\mathrm{Au}}\right)_{2}, \mathrm{~m} / \mathrm{z}=1562(\mathrm{~m} / 2)$ and (b) $\mathrm{C}_{18}-\left(\mathrm{PEP}_{\mathrm{Au}}{ }^{\mathrm{M}-\mathrm{Ox}}\right)_{2}, \mathrm{~m} / \mathrm{z}=$ $1578(\mathrm{~m} / 2)$. 


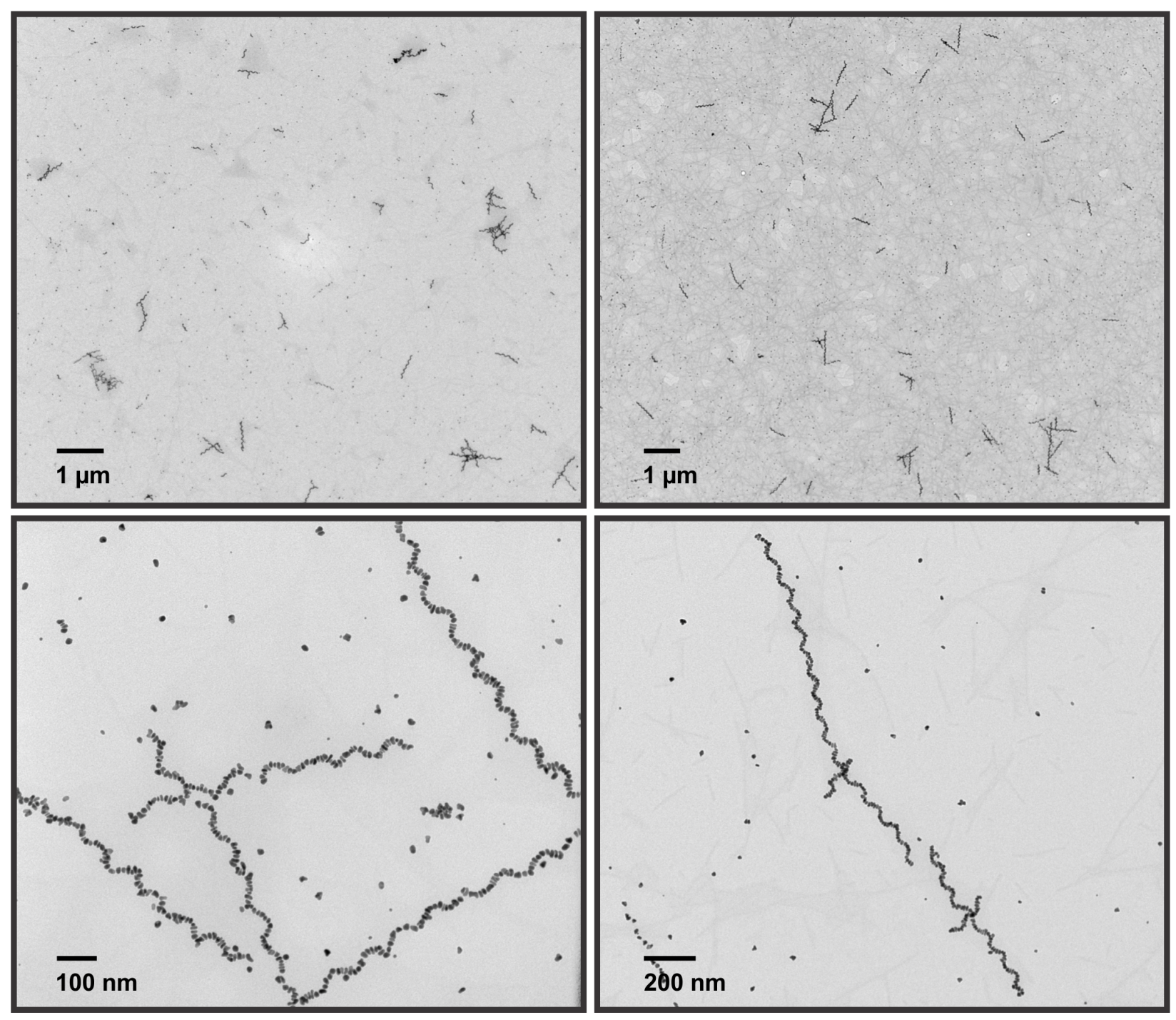

Figure S3. Additional TEM images of the single-helical superstructure at different magnifications. 


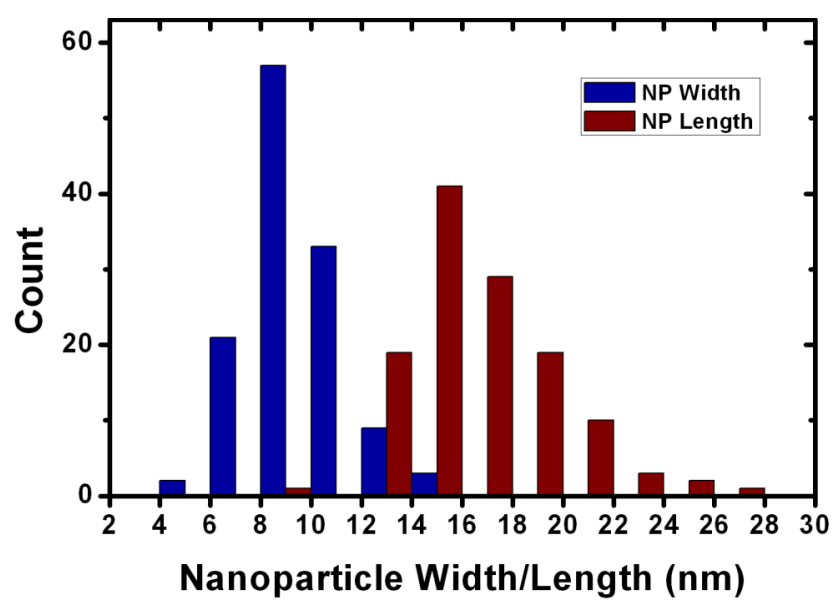

Figure S4. The nanoparticle length and widths of the single-helical superstructure were $16.6 \pm$ $3.0 \mathrm{~nm}$ and $9.6 \pm 1.9 \mathrm{~nm}$, respectively, after 15 hours of reaction (based on 125 counts each).

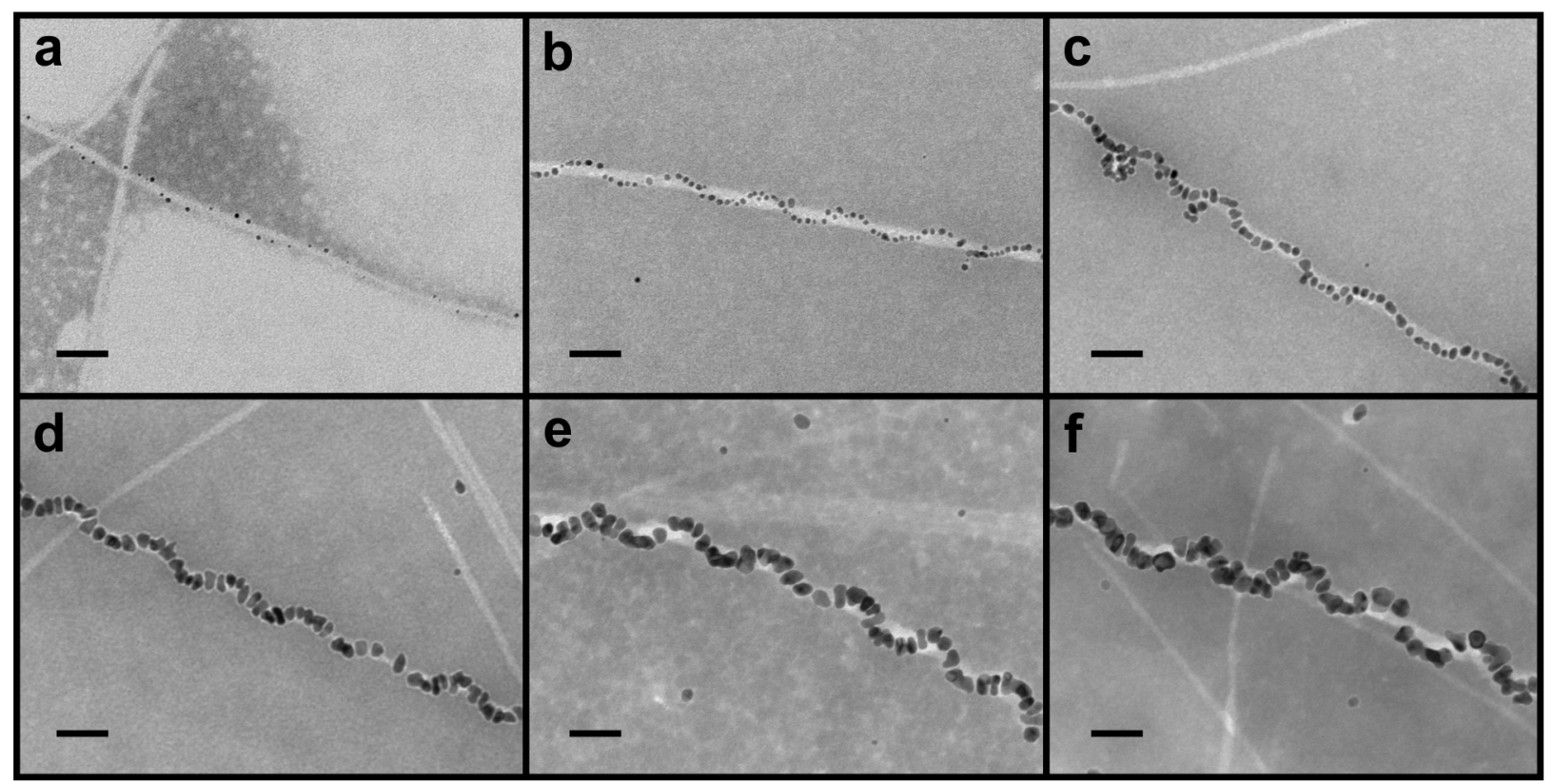

Figure S5. Negative stained TEM images of the single helices after (a) 0 min., (b) 30 min., (c) 2 hrs., (d) 5 hrs., (e) 8 hrs., and (f) 2 days of reaction at room temperature (scale bar $=50 \mathrm{~nm}$ ). 
a

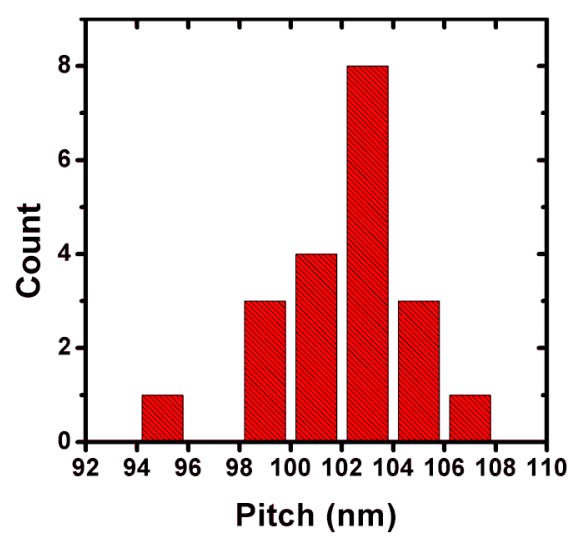

b

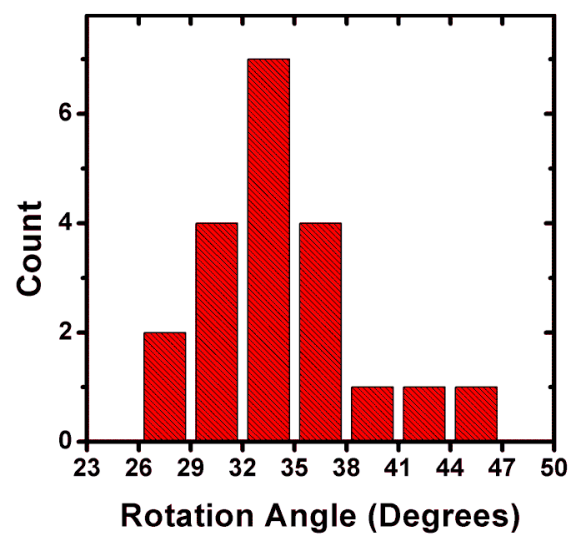

C

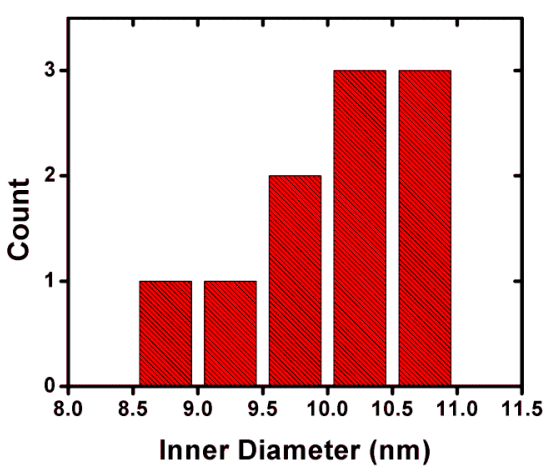

Figure S6. Structural parameters of single helices from cryo-ET: (a) the helical pitch was 102.0 $\pm 2.5 \mathrm{~nm}$, based on 20 counts; (b) rotation angle was $34.3 \pm 4.9$ degrees, based on 20 counts; and (c) inner diameter was $10.1 \pm 0.6 \mathrm{~nm}$, based on 10 counts. 

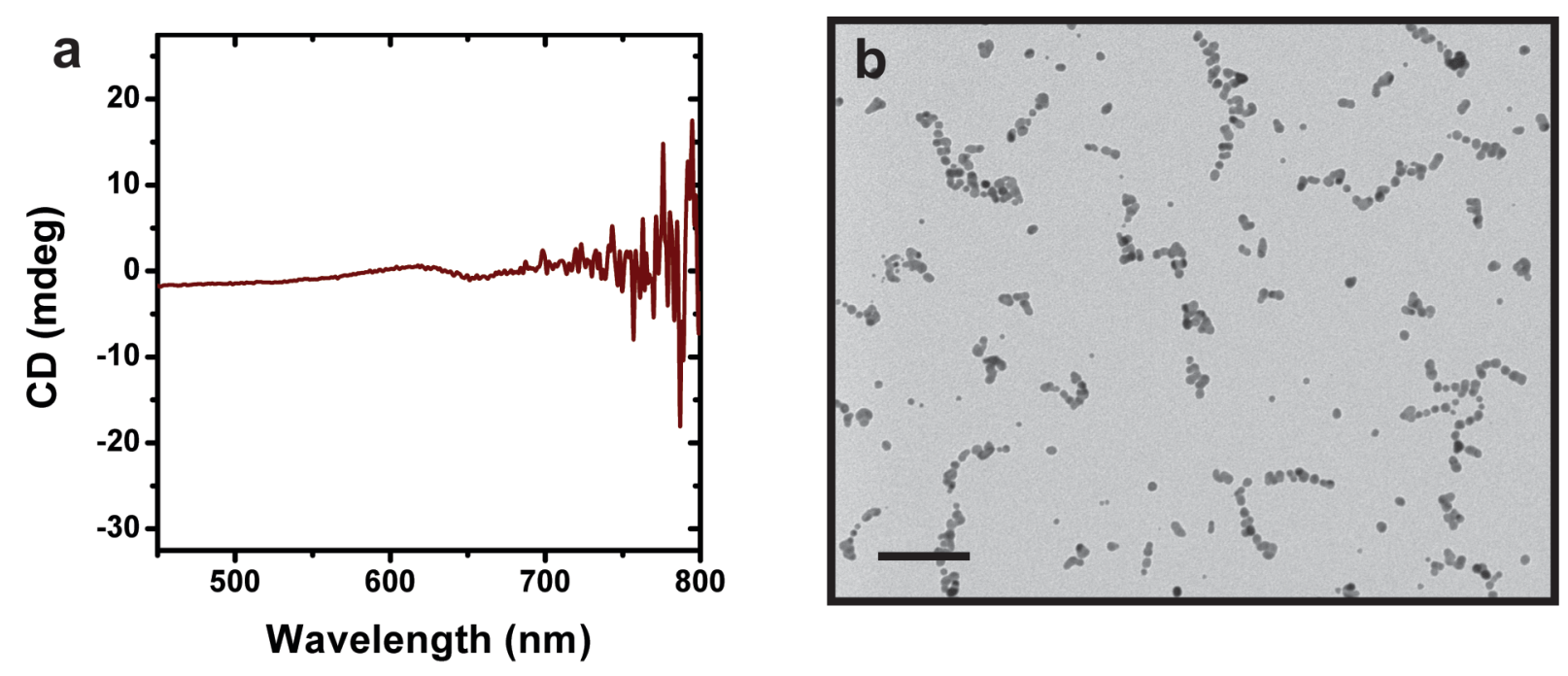

Figure S7. (a) CD spectrum of $\mathrm{PEP}_{\mathrm{Au}}{ }^{\mathrm{M}-\mathrm{ox}}$ capped gold nanoparticles and (b) their corresponding TEM image $($ scale bar $=100 \mathrm{~nm})$. Both single particles and particle aggregates are observed. 
a

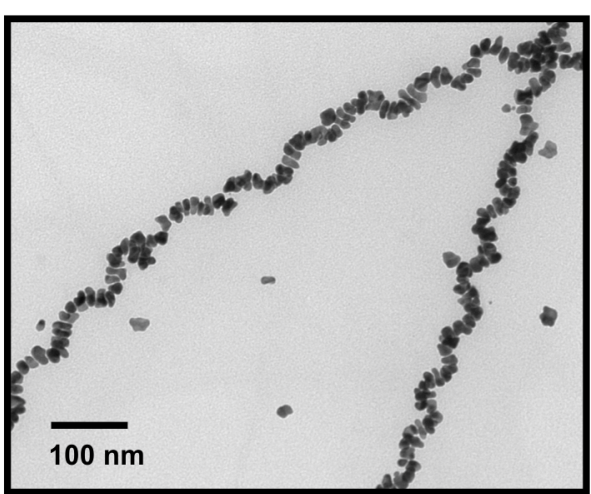

b

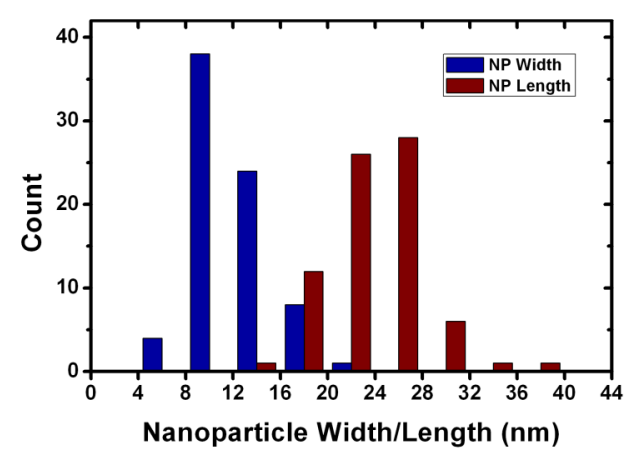

C

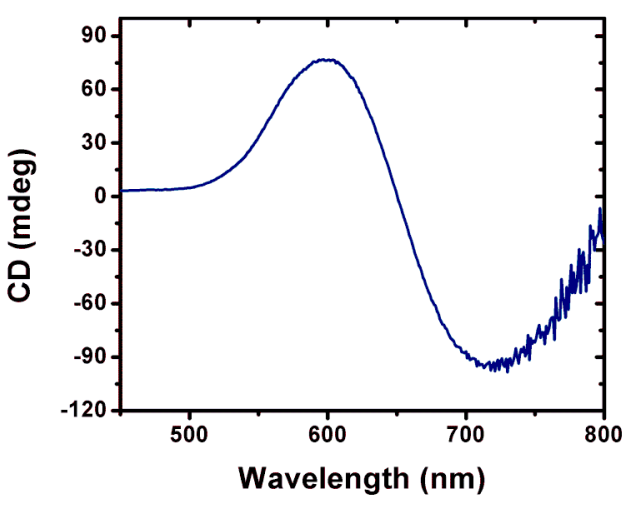

d

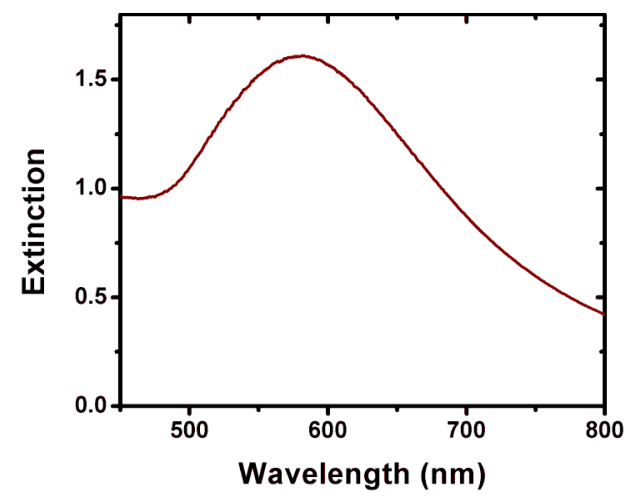

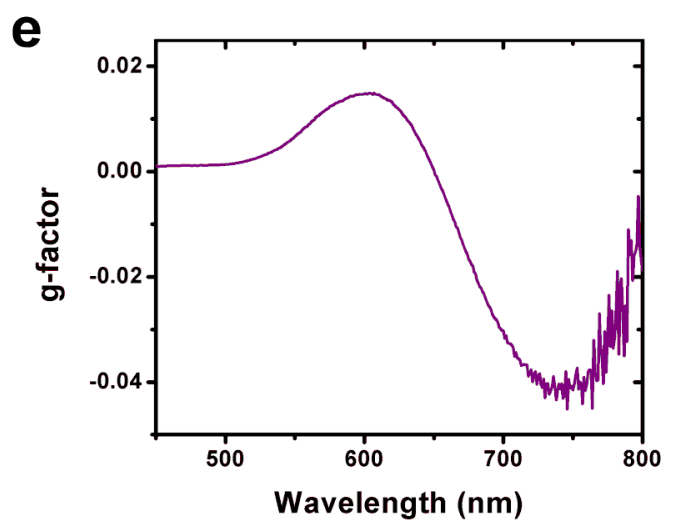

Figure S8. (a) TEM image of helices formed with $10 \mathrm{~min}$. of sonication and $20 \mathrm{~min}$. of incubation prior to $\mathrm{HAuCl}_{4} / \mathrm{TEAA}$ addition. (b) The particle width and lengths were $12.1 \pm 3.0$ $\mathrm{nm}$ and $23.9 \pm 3.9 \mathrm{~nm}$, respectively (based on 75 counts, each). (c) CD spectrum of the optimized single helices exhibit a very strong CD signal. (d) UV-Vis extinction spectrum, and (e) g-factor graph showing absolute g-factor values up to 0.04 . g-factor $=\Delta \varepsilon / \varepsilon$, where $\Delta \varepsilon$ is the molar circular dichroism and $\varepsilon$ is the molar extinctions. 

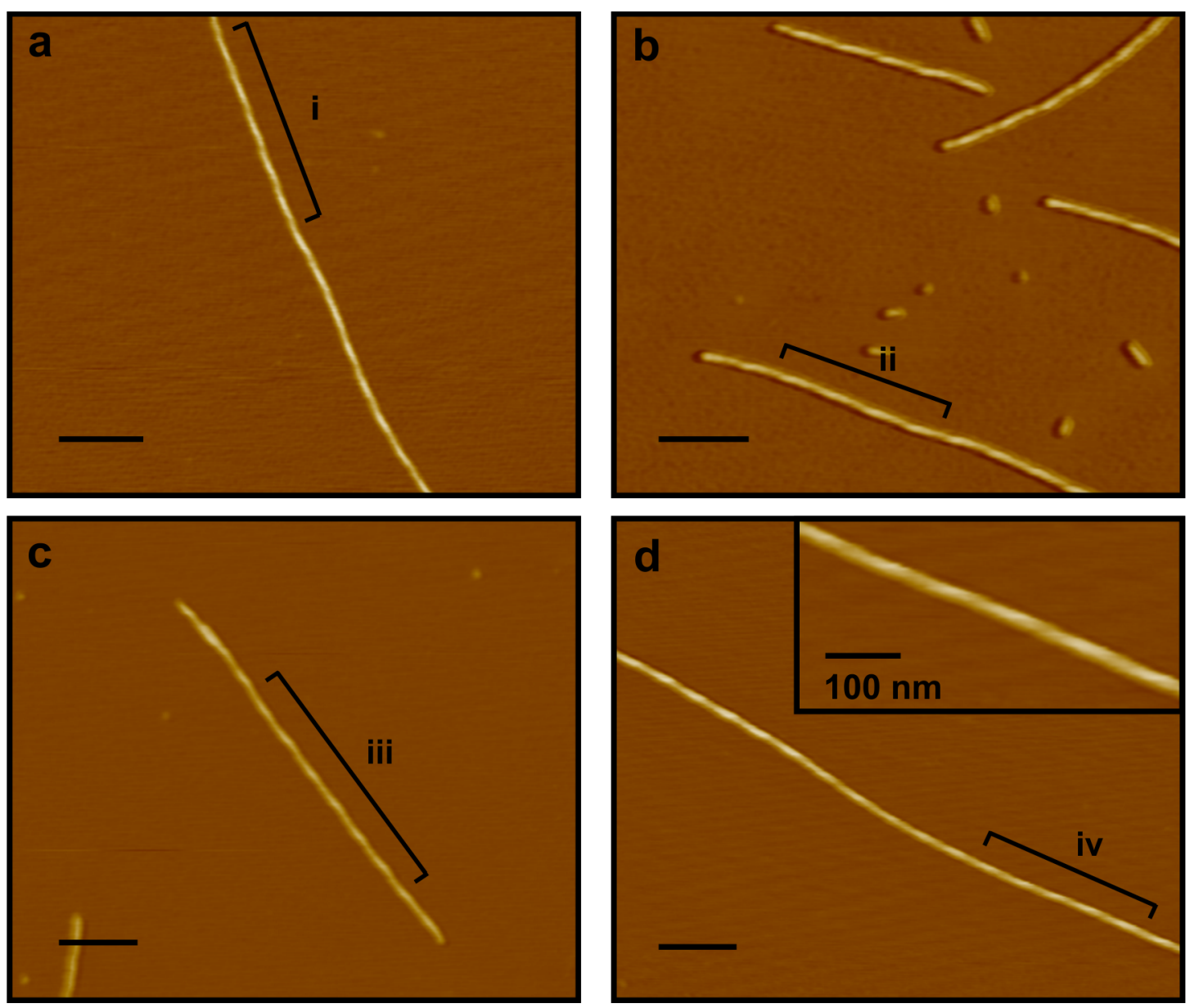

e
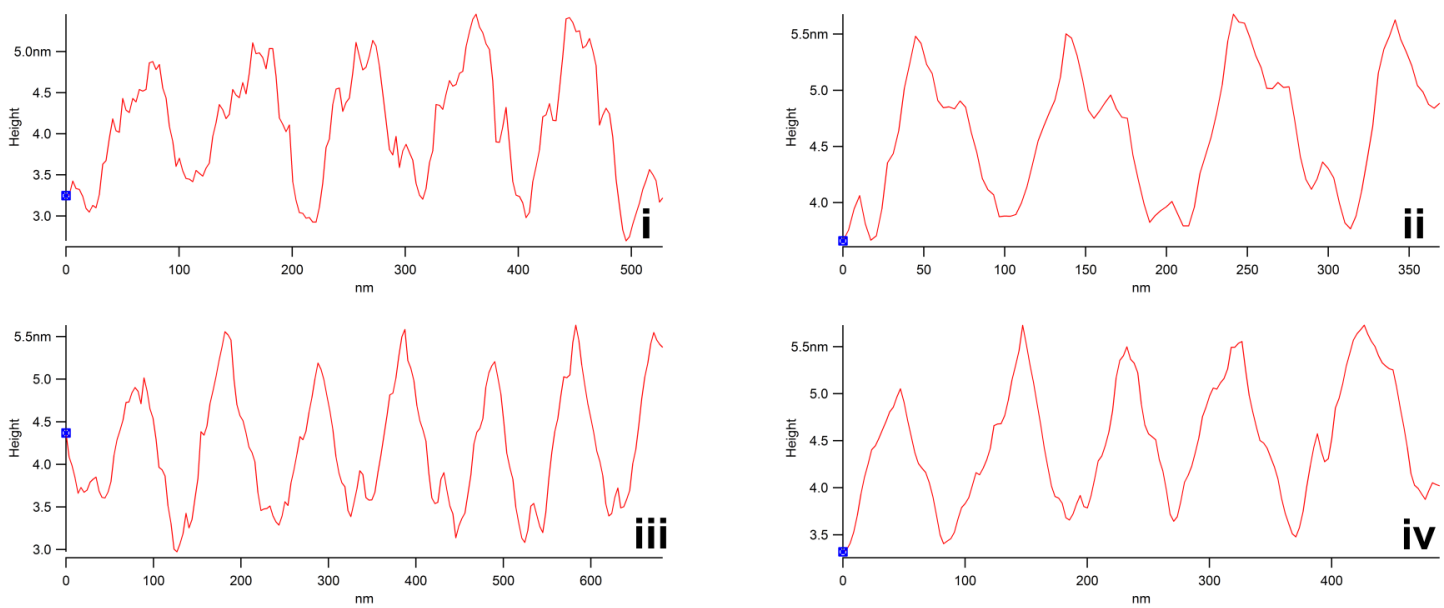

Figure S9. (a-d) AFM images of $\mathrm{C}_{18}-\left(\mathrm{PEP}_{\mathrm{Au}}^{\mathrm{M}-\mathrm{Ox}}\right)_{2}$ fibers dispersed on APTES-functionalized mica (scale bar $=200 \mathrm{~nm}$ ) and (e) height traces of the labeled segments. 


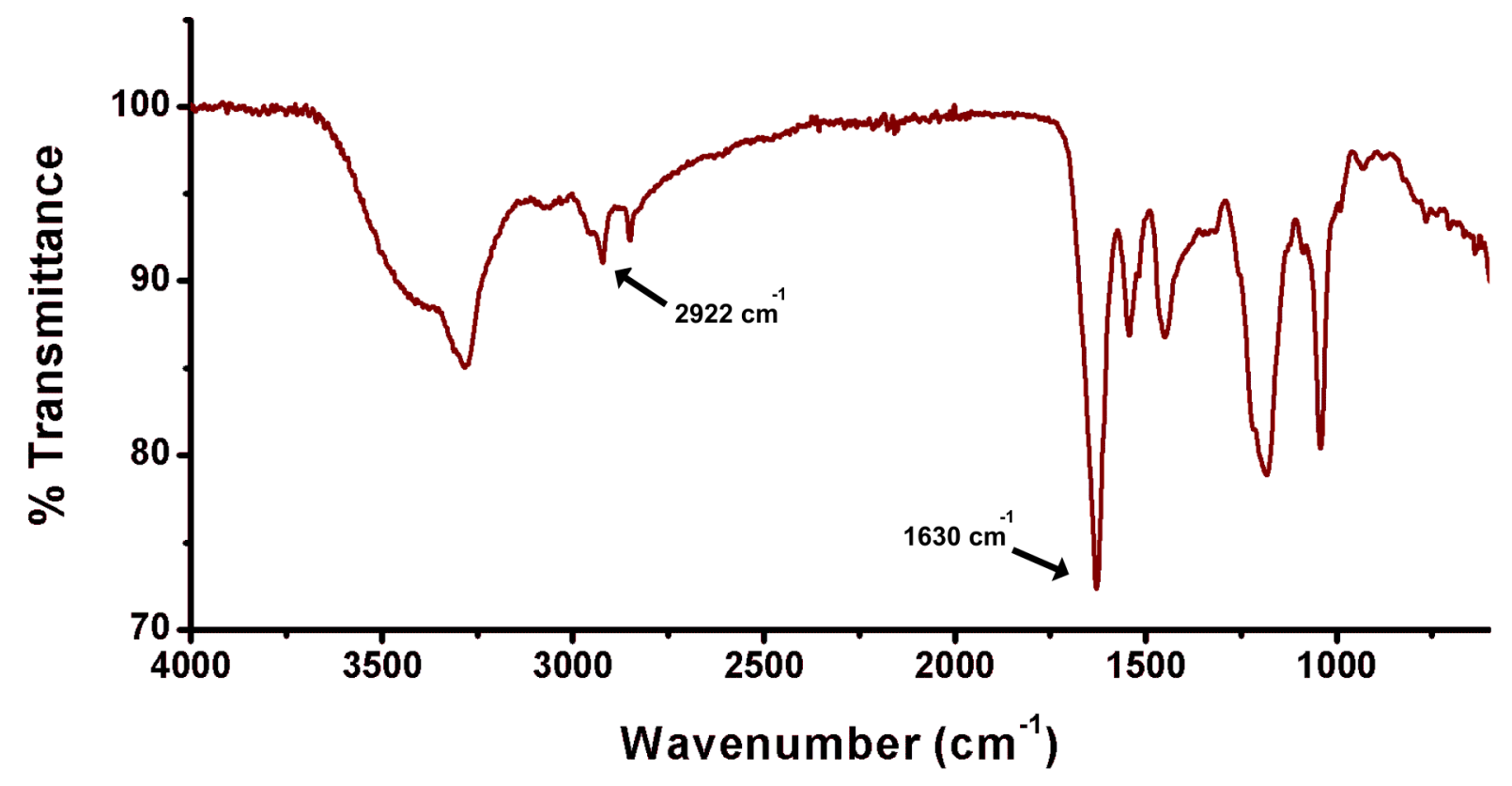

Figure S10. FTIR spectrum of $\mathrm{C}_{18}-\left(\mathrm{PEP}_{\mathrm{Au}}^{\mathrm{M}-\mathrm{Ox}}\right)_{2}$ fibers. Peaks at $1630 \mathrm{~cm}^{-1}$ and $2922 \mathrm{~cm}^{-1}$ correspond to the amide I band and $\mathrm{C}-\mathrm{H}$ stretch, respectively.

a

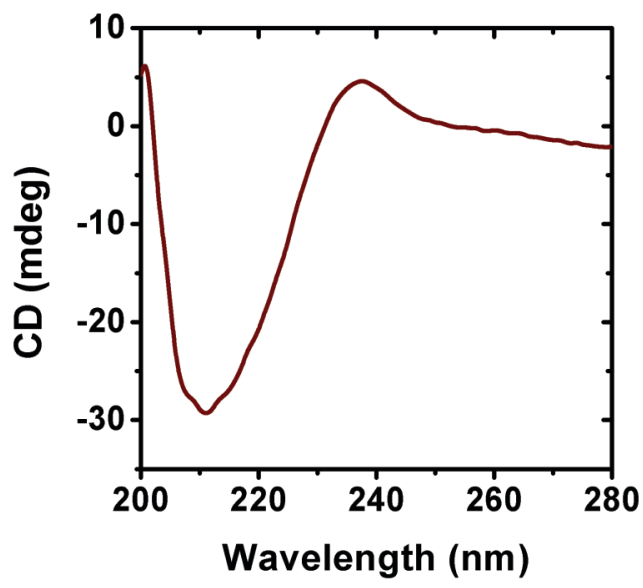

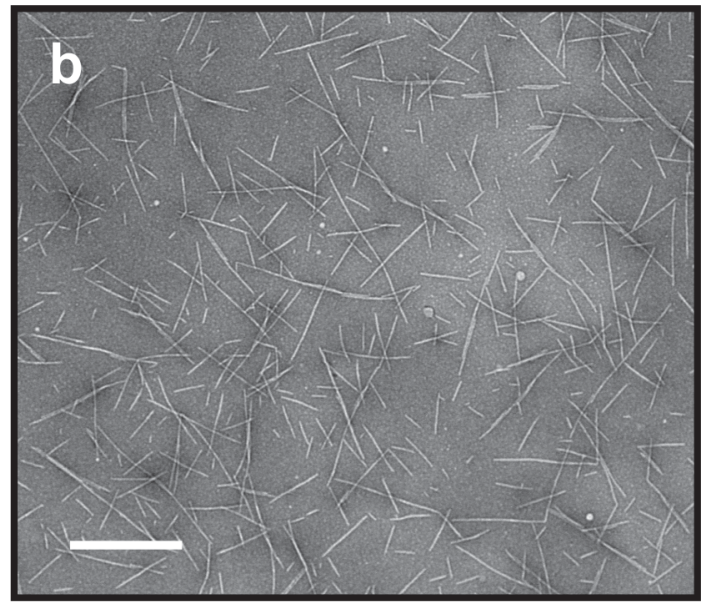

Figure S11. (a) CD spectrum of $\mathrm{C}_{18}-\left(\mathrm{PEP}_{\mathrm{Au}}^{\mathrm{M}-\mathrm{Ox}}\right)_{2}$ in $10 \mathrm{mM}$ HEPES and $1 \mathrm{mM} \mathrm{CaCl} \mathrm{Cafter}_{2}$ one day, and (b) corresponding negative stained TEM image ( scale bar $=500 \mathrm{~nm})$. 

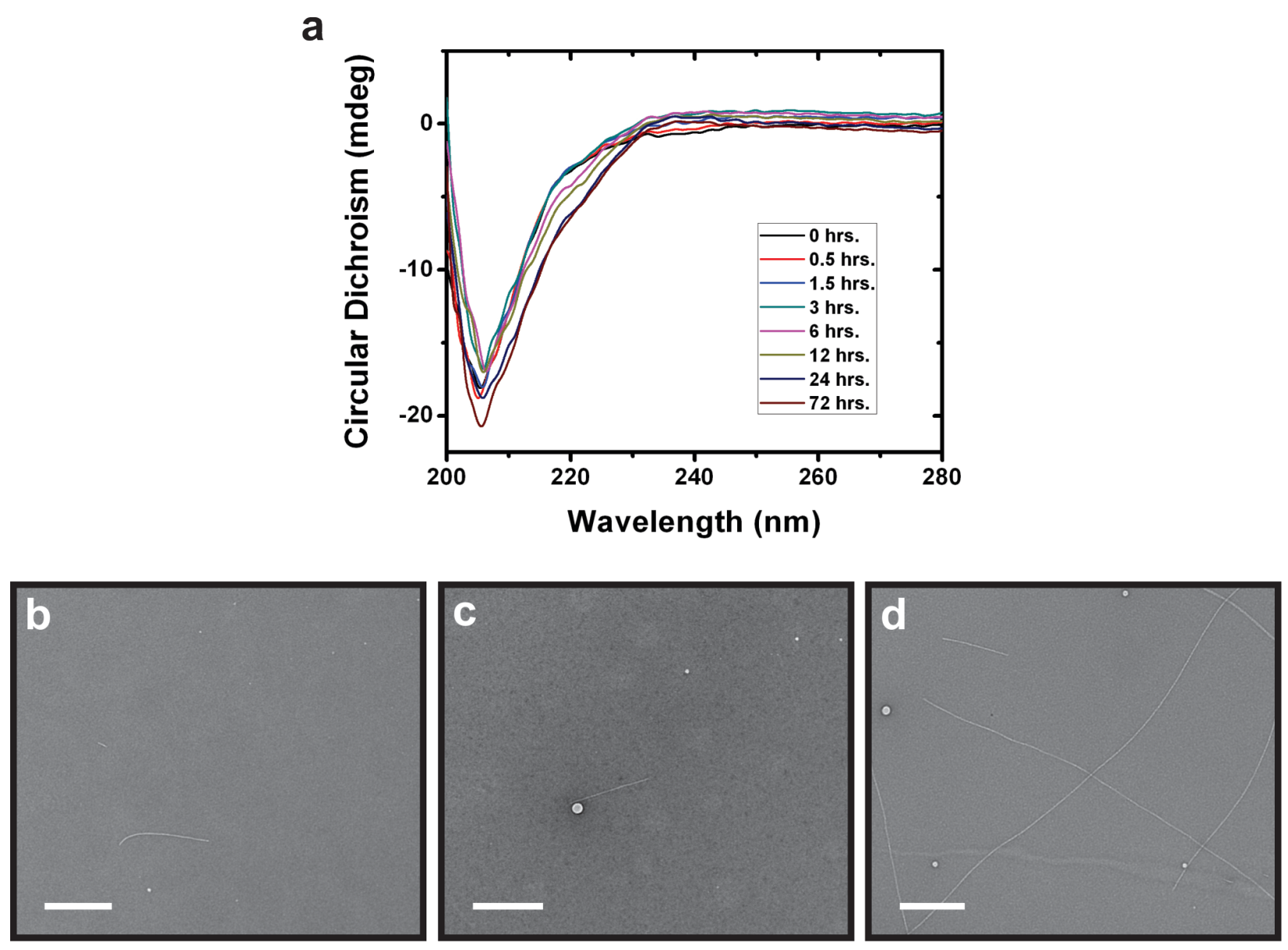

Figure S12. (a) $\mathrm{CD}$ spectra of $\mathrm{C}_{18}-\left(\mathrm{PEP}_{\mathrm{Au}}^{\mathrm{M}-\mathrm{Ox}}\right)_{2}$ in $10 \mathrm{mM}$ HEPES as a function of time. Negative stained TEM images after (b) 15 min., (c) 3 hrs., and (d) 72 hrs. are shown (scale bar = $500 \mathrm{~nm}$ ). Under these conditions, fibers form very slowly, and very few fibers are observed at early time points. 
a

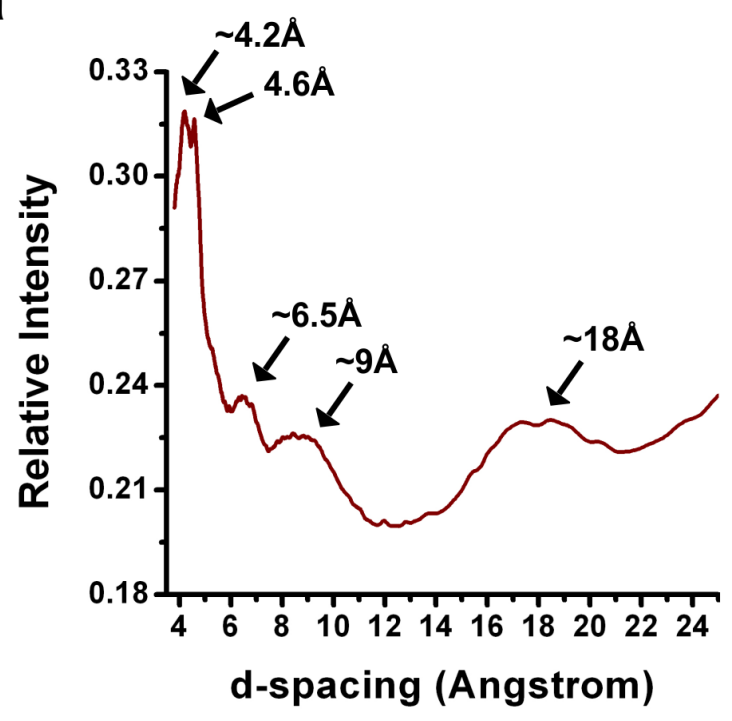

b

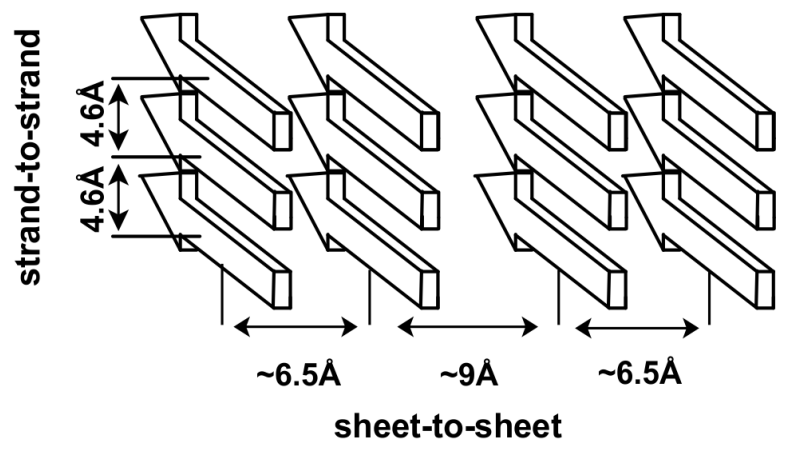

Figure S13. (a) Integrated d-spacings of the XRD diffractogram. (b) Figure showing the strandto-strand and sheet-to-sheet distances as revealed via XRD. 

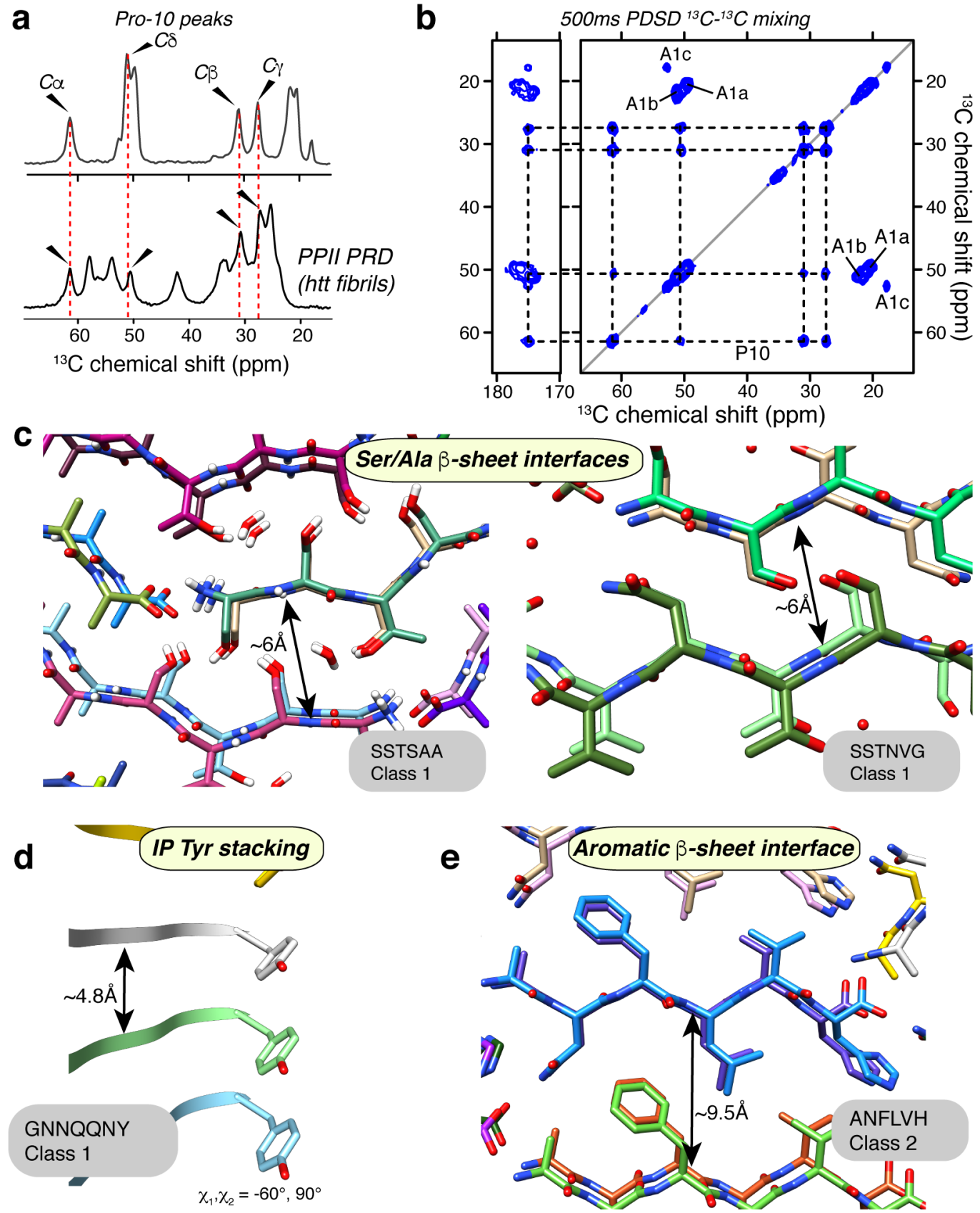

Figure S14. Additional ssNMR results and structural reference. (a) Aliphatic ${ }^{13} \mathrm{C}$ 1D MAS ssNMR spectrum of the site-specifically labeled $\mathrm{C}_{18}-\left(\mathrm{PEP}_{\mathrm{Au}}{ }^{\mathrm{M}-\mathrm{Ox}}\right)_{2}$ assemblies (top), with the $\mathrm{P} 10$ peaks indicated. Bottom: ssNMR spectrum of fibrillar huntingtin exon1-derived peptide $\mathrm{htt}^{\mathrm{NT}} \mathrm{Q}_{30} \mathrm{P}_{10} \mathrm{~K}_{2}$, with ${ }^{13} \mathrm{C},{ }^{15} \mathrm{~N}$-labeled Pro P48 (Adapted from ref. ${ }^{1}$ ). In both cases the labeled Pro is part of a PPII helix that flanks the $\beta$-sheet amyloid core. (b) Long-mixing 500ms PDSD 2D 
ssNMR spectrum on the labeled $\mathrm{C}_{18}-\left(\mathrm{PEP}_{\mathrm{Au}}{ }^{\mathrm{M}-\mathrm{Ox}}\right)_{2}$ assemblies. Compared to the short-mixing spectrum (Figure 5b) only new intra-residue P10 peaks are observed, with no contacts between the distinct A1 conformers. (c) Compact zipper interfaces mediated by Ser and other small amino acids in amyloid-like crystals of peptides SSTSAA and SSTNVG from RNase and IAPP. ${ }^{2}$ The compact $6 \AA$ inter-sheet distance is indicated. (d) Tyr ring stacking in GNNQQNY in-register parallel (IP) $\beta$-sheets. ${ }^{3}$ (e) Amyloid interfaces featuring aromatic residues generate wider 9-10 $\AA$ inter-sheet distances. Illustrated for Phe in this Class-2 amyloid-like crystal of peptide ANFLVH. ${ }^{4}$ The PDB entries for the four peptide crystal structures are 2ONW, 3DG1, 1YJP, and $5 \mathrm{E} 5 \mathrm{X}$. 


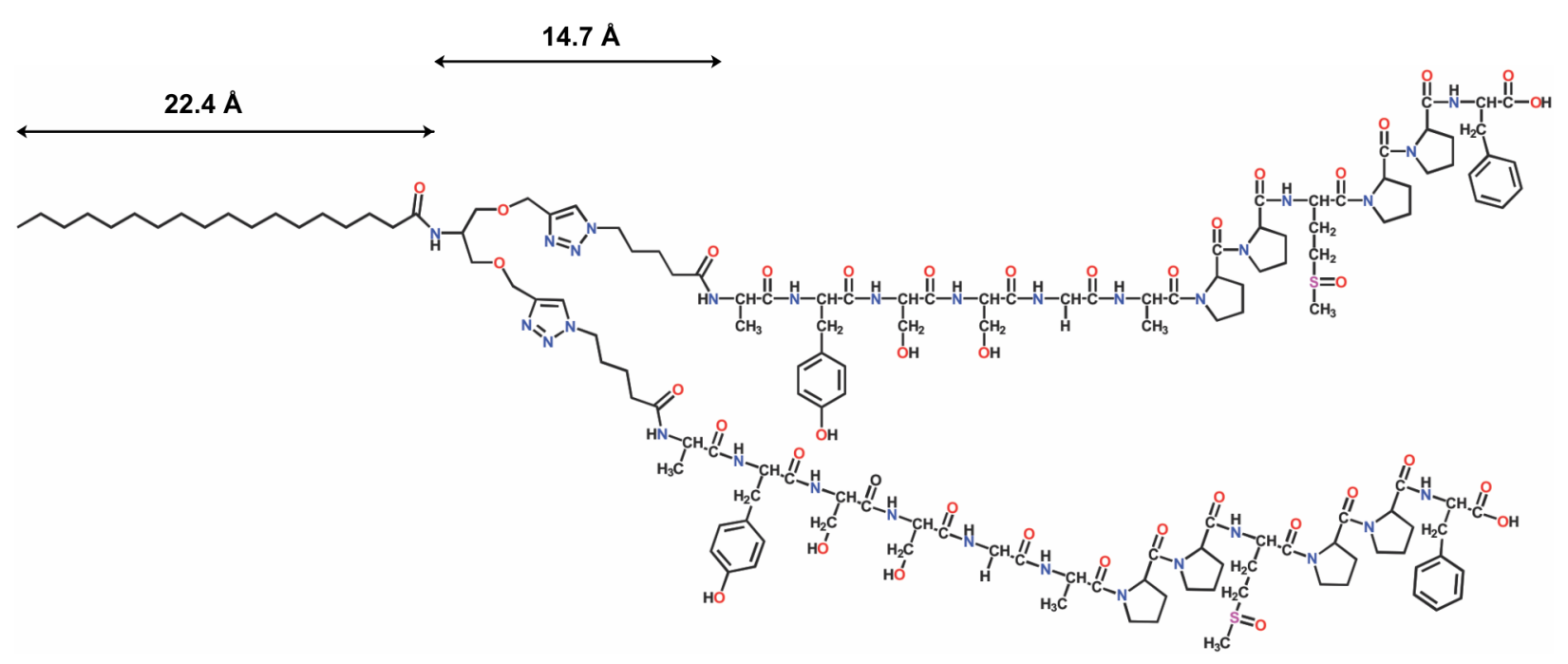

Figure S15. Length of the different extended segments of $\mathrm{C}_{18}-\left(\mathrm{PEP}_{\mathrm{Au}}^{\mathrm{M}-\mathrm{Ox}}\right)_{2}$. The total length of the extended molecule is $\sim 7.5 \mathrm{~nm}$. The length measurement of the peptide portion takes into account the average length spanned by one amino acid in both the parallel $\beta$-sheet $(3.25 \AA)^{5}$ and the PPII $(3.1 \AA)^{6}$ secondary structure. 
Table S1. Detailed experimental conditions of the MAS ssNMR experiments. Abbreviations:

NS, number of scans; Set Temp, set temperature of cooling gas; MAS, magic angle spinning rate;

$R D$, recycle delay; TPPM, two-pulse phase-modulated ${ }^{I} H$ decoupling power during evolution and acquisition ; $t_{1}$ evol., number of evolution time increments and increment size in the indirect dimension.

\begin{tabular}{|c|c|c|c|c|c|c|c|c|c|}
\hline Figure & Expt. & NS & $\begin{array}{l}\text { Set Temp } \\
\text { (K) }\end{array}$ & $\begin{array}{l}\text { MAS } \\
\text { (kHz) }\end{array}$ & $\begin{array}{l}\text { RD } \\
\text { (s) }\end{array}$ & $\begin{array}{c}\text { TPPM } \\
(\mathrm{kHz})\end{array}$ & $\begin{array}{c}\mathrm{t}_{1} \text { evol. } \\
(\mu \mathrm{s})\end{array}$ & $\begin{array}{l}\text { DARR mixing } \\
\text { time (ms) }\end{array}$ & $\begin{array}{c}{ }^{1} \mathbf{H}-{ }^{13} \mathbf{C} \text { Contact } \\
\text { time (ms) }\end{array}$ \\
\hline $5 \mathrm{~b}$ & $\begin{array}{c}2 \mathrm{D}^{13} \mathrm{C}^{-13} \mathrm{C} C \mathrm{CP}- \\
\text { DARR }\end{array}$ & 64 & 277 & 10 & 3 & 83 & $562 * 35.6$ & 20 & 2 \\
\hline S14-a & ${ }^{1} \mathrm{H}-{ }^{13} \mathrm{C} \mathrm{CP}$ & 1024 & 277 & 10 & 3 & 83 & NA & $\mathrm{NA}$ & 2 \\
\hline S14-b & $2 \mathrm{D}{ }^{13} \mathrm{C}-{ }^{13} \mathrm{C}$ PDSD & 64 & 277 & 10 & 3 & 83 & $562 * 33.11$ & 500 & 2 \\
\hline
\end{tabular}

\section{References}

1. Hoop, C. L.; Lin, H.-K.; Kar, K.; Hou, Z.; Poirier, M. A.; Wetzel, R.; van der Wel, P. C. A. Biochemistry 2014, 53 (42), 6653-6666.

2. Sawaya, M. R.; Sambashivan, S.; Nelson, R.; Ivanova, M. I.; Sievers, S. A.; Apostol, M. I.; Thompson, M. J.; Balbirnie, M.; Wiltzius, J. J. W.; McFarlane, H. T.; Madsen, A. O.; Riekel, C.; Eisenberg, D. Nature 2007, 447 (7143), 453-457.

3. Nelson, R.; Sawaya, M. R.; Balbirnie, M.; Madsen, A. O.; Riekel, C.; Grothe, R.; Eisenberg, D. Nature 2005, 435 (7043), 773-778.

4. Soriaga, A. B.; Sangwan, S.; Macdonald, R.; Sawaya, M. R.; Eisenberg, D. The Journal of Physical Chemistry $B 2015$.

5. Nesloney, C. L.; Kelly, J. W. Bioorganic \& Medicinal Chemistry 1996, 4 (6), 739-766.

6. Adzhubei, A. A.; Sternberg, M. J. E.; Makarov, A. A. Journal of Molecular Biology 2013, 425 (12), 2100-2132. 